Acta Linguistica Hungarica, Vol. 52 (4), pp. 341-366 (2005)

\title{
COGNITIVE GRAMMAR: THE STATE OF THE ART AND RELATED ISSUES: AN INTERVIEW WITH RONALD LANGACKER*
}

\author{
JÓZSEF ANDOR
}

\begin{abstract}
In this interview with the founder of cognitive grammar as a model of description the following major issues have been raised and discussed: (i) relations between models of cognitive linguistics: cognitive grammar vs. construction grammar; (ii) the nature of lexical representation: the scope of wordhood vs. expressions; (iii) the nature and role of domains vs. types of conceptual structure such as scenes, frames, and scripts; (iv) the status and scope of active zones in linguistic description; (v) the nature of economy in linguistic representation at various levels - lexical semantic vs. lexical pragmatic issues; (vi) the treatment of part of speech relatedness in cognitive grammar, with special emphasis on the status of adjectives; (vii) the notion of linguistic modularity.
\end{abstract}

ANDOR: Thank you very much for accepting my call for an interview. I am honored to have a chance to talk to one of the founding fathers of cognitive linguistics, founder of the paradigm called cognitive grammar, in Budapest. My first question particularly concerns the relation between cognitive linguistics and cognitive grammar itself as a model. In the course of the past few decades cognitive-based studies of language have gained more and more ground, mainly as an alternative to the Chomskyan type of generative grammar and other types of formalistic or logically based linguistic theoretical paradigms. A number of models have been presented. We have to note, however, that an important common feature of all of them is that they are deeply rooted in studying the cognitive sources or bases of language, linguistic representation and expressibility. That is to say, they all share a common core: cognition. How do you view your own model, that of cognitive grammar, which I think constitutes one

* This interview was recorded at Eötvös Loránd University, Budapest, on December 6, 2004. Special thanks go to Professor Zoltán Kövecses in helping to organize it. 
of the mainstreams of research with such a bias, among the varieties of models of cognitive linguistics? Basically, I would like you to comment on the relation and differences between the so-called 'cognitive linguistics' and 'cognitive grammar'.

LANGACKER: I am not sure that there are differences. How much is subsumed under cognitive linguistics, of course, is a very flexible matter. It could be construed very broadly. Some people would include, for example, Jackendoff's work under cognitive linguistics. I generally include Anna Wierzbicka's work under cognitive linguistics, and construction grammar in its various guises. So it is a broad view that could be construed more narrowly, e.g., to include people who would normally go to the ICLC (the International Cognitive Linguistics Conference). That would, for example, exclude Jackendoff, and I would also exclude him from cognitive linguistics (in the narrower sense) due to his belief in the autonomy of grammar. Thus, instead of saying that cognitive grammar is different from cognitive linguistics, I would say that it is only one version of it. Arguably, however, it is the best articulated and worked out as a comprehensive framework, with the possible exception of construction grammar (in which many more people are specifically working). Cognitive grammar is meant to be a potentially comprehensive model of language structure. I've tried to design it in such a way that it can be an umbrella for all the varied research done in cognitive and even functional linguistics. Many different levels and dimensions of linguistic structure can be approached through cognitive grammar, even if they have not been equally explored. For example, there can and should be a cognitive phonology. I have discussed numerous aspects of phonology in various places, although I have not tried to work out a comprehensive account (not having been trained as a phonologist). I think there can and will eventually be a cognitive lexicography using the ideas of cognitive grammar. Sociolinguistic questions, diachronic problems like grammaticization, language acquisitionthese can all be approached using the cognitive grammar framework. So even though relatively few people in cognitive linguistics actually do cognitive grammar per se and work out descriptions in terms of it, I still think of it as a potential umbrella, as something which can ultimately model the various results being achieved in cognitive linguistics.

ANDOR: Recently, one can experience some sort of a merging, or at least some sort of a linking between cognitive grammar and a more and more intensively emerging field: construction grammar. You yourself tackled the relations between these models in your plenary lecture given 
recently at an important conference on cognitive linguistics in Logroño, Spain (2003). Let me add to this that Ray Jackendoff, who still considers himself a generativist, has also recently expressed his sympathy with constructionist types of grammar. Do you think that construction grammar, as outlined by Croft, Goldberg and others, and your model of cognitive grammar should go together as parallel, but quite closely related models, or perhaps, that they could or even should be merged in some way?

LANGACKER: I think you have to separate the basic idea of constructionism from the more general ideas of cognitive grammar and cognitive linguistics. Even people in generative grammar now talk more in terms of templates and constraints than in terms of rules (in the classic sense of rewriting rules and derivations from underlying structures). So I think the basic idea has basically been established quite broadly. It was fundamental to cognitive grammar from the start, many years ago. It has become common even in generative approaches. And of course it is a basic notion of Fillmore's construction grammar: the idea that constructions are the basic objects of description is one parallelism between construction grammar and cognitive grammar.

ANDOR: I did not refer to Fillmore as he never published the book version of it.

LANGACKER: That's right. In any case, these ideas were worked out independently at about the same time. I didn't talk about 'constructions' as the object of description - that was originally Fillmore's term. I never thought to use the term, but if you look at my model, that's exactly what it is, of course. So there are many similarities between construction grammar (in all its versions) and cognitive grammar, just because of that common starting point: constructions as the basic objects of description, as well as a basic vehicle of description. Also the idea that constructions reduce to form-meaning pairings. That's a common idea, up to a point. There are also many differences which I have talked about in various places, one being that paper from the Logroño conference, which will soon be published in a volume based on the conference proceedings.

There I looked particularly at Croft's radical construction grammar (2001) and Goldberg's version of classic construction grammar (1995). There's one major difference, which is really the fundamental difference between cognitive grammar and those other kinds of construction grammar. It reflects the fact that Fillmore and the people who have followed him have never even tried to totally reduce grammar to meaning and symbolic relationships. There are still - and this is what I tried to point 
out at various places - vestiges of autonomous grammar in construction grammar. As formulated, this is true of both Croft's version and Goldberg's version. It is apparent when they talk about what goes into a form-meaning pairing. As for meaning, people working in construction grammar tend not to do very much with it, at least with meaning in my sense of the term. They don't get into the details of construal, and they usually don't bring in metaphor, fictivity, or mental spaces. These fundamental matters tend to be omitted in construction grammar, at least in practice. I don't know how people feel about it in principle. But certainly, basic ideas like construal, profiling, trajector-landmark organization, perspective, metaphor, etc. are not very visible in their analyses. Still, there is agreement that meaning figures in grammatical description. Now what about form? In discussions of construction grammar, what is referred to as 'form' includes not just phonology, but also grammatical form. Indications of grammatical category (like noun and verb) and grammatical relations (like subject and object) are adopted as semantically unanalyzed notions. Though subsumed under form, they are not phonological and not perceptually observable. What I tried to show in the paper mentioned, among other things, was that in cognitive grammar 'form' is limited to phonology and other symbolizing structures - e.g., gesture - but does not include syntactic categories, nor grammatical relations. Despite the traditional terminology, referring to these as matters of 'form' is inappropriate. I analyze those notions in terms of symbolic relationships. A noun, for example, is not something which has a meaning, a phonological representation, and another aspect of form, namely its status as a noun. Rather, it is something which has a meaning and a phonological representation, being a noun precisely because of what kind of meaning it has. Status as a noun is not something distinct. So, whereas in the other versions of construction grammar the 'form' part of form-meaning pairings includes aspects of grammar, for me form is limited to phonology (and other symbolizing structures). All aspects of grammar are inherent in the pairing of those other two. Grammar is not something that participates in symbolic relationships as part of what is doing the symbolization. Rather, it is implicit in the symbolic relationships themselves, where these reduce to meanings and phonological structures.

ANDOR: One of the interesting issues related to your theory concerns the status and scope of the linguistic notion and concept of 'word'. You don't seem to use the notion to serve as a linguistic unit. What you do use, 
systematically, is the term 'expression'. However, 'expression' seems to have a broader status in your theory. One can say, it has even a different scope. I mean, even full utterances can be taken to be expressions, but single lexical items can also have such a status. If I understand you correctly, expressions emerge as units in discourse, which suggests to me that they are units of performance, and that thus they have a high rate of flexibility of content under the dominance of the particular 'domain' that they linguistically map. Can you clarify and outline the notions of 'expression' and 'lexical item' as linguistic units in your view (you do tend to use the term 'lexical item' rather than 'word' in your papers and books - 1987, 425-8; 1990; 1999a, b), and reflect on their relation to the conventional notion of wordhood? Actually, let me note that John Taylor, who is also a cognitivist, uses the term 'word' in Chapter 9 of his voluminous textbook on cognitive grammar published in 2002 and elsewhere (talking about the taxonomy of symbolic units), and you cannot find the term 'expression' in the index of that book.

LANGACKER: Well, Taylor was doing what he was doing for purposes of writing a textbook, and I think he was probably following the traditional textbook practice of talking about words in a rather informal way. Let me not address that seriously; I think that was done for practical reasons.

First, a preliminary terminological point. I use the term 'unit' in a technical sense, as something which has become an established cognitive routine. So technically speaking, a novel expression cannot be a unit, nor can we talk of "units of performance".

Now, the word 'word' is very much abused by linguists in writing textbooks and elsewhere. It's very common in textbooks of English to talk about lexical items as words. You can get away with that in English, because so many lexical items are pretty much coextensive with words, we don't have a highly inflected morphology, and so on. But in general we need to distinguish a 'lexical item' or 'lexeme' from a 'word'. In polysynthetic languages, or any language with a lot of complex morphology, a 'word' is usually a 'novel expression' in some way. There is typically a lexical stem plus a number of derivational and inflectional elements, and while each of these is familiar individually the totality is quite often novel. So for me - and I'm being conservative here - a word is the kind of thing you would write with spaces around it in a European language. Or to take the classic Bloomfieldian definition, a word is a minimal free form, and a word boundary a natural place to pause (1933, 177-89). I think a word is a kind of psychological unit, at least in certain kinds of 
languages. And for me it's basically a phonological unit. I don't have much by way of a cognitive grammar analysis, so I haven't used it or tried to define it technically. But I do mean to limit "word' to "words" in the ordinary sense of the term, things you write with spaces (assuming the practice were rationalized a bit). Understood in this way, we cannot talk about a language consisting of words, or people just producing words. You need some other term for what I call 'expressions'. You are right that the term 'expression' is used very broadly here. Besides words, it includes phrases, entire sentences, entire utterances, i.e., any kind of utterance of any size. There is no reason why sequences of sentences could not be called 'expressions', but in practice I use the term only up to the sentence level. And you do need some term: if you want to talk about grammar in a general way, you cannot talk just about words, or about phrases, or about clauses. You need something for raw data of any size, and 'expression' is what I use. It's not really a technical term, so I haven't defined it carefully, but in volume 1 of Foundations there is quite a long section about the subtleties of this notion $(1987,425-8)$. It is not self-explanatory, and what counts as an 'expression' depends on the purpose of one's analysis, how closely you look at the data.

In my view terms like 'lexical item' and 'lexicon' are also much abused, being used in different ways often based on gratuitous assumptions. The only definition that makes sense to me, one that is useful and approximates the traditional understanding of it, is to define a 'lexical item' as a 'fixed expression'. It's not coextensive with 'word', it's not coextensive with expressions that are in some way unpredictable or irregular. For me, then, a 'lexical item' is something you would list in a dictionary as a fixed expression - an expression that people learn as a unit, regardless of its size. In many languages it is typically smaller than a word, but there is no reason not to regard fixed expressions larger than words as lexical items, since there is no natural stopping point. So these terms have different functions, and I try to use all of them in a fairly traditional and consistent sense. A 'word' is basically a phonological unit, 'expression' is a general term for sequences that are produced and need to be analyzed, and 'lexical items' are fixed expressions.

ANDOR: With this notion of expressions and wordhood as outlined, what do you think of the role and status of dictionaries as linguistic aids for native and non-native speakers of a language? What do they represent? And, in particular, what sort of, what type of information should they represent? Ongoing research in frame-based semantics, which I would 
rather term 'frame-based pragmatics', suggests that dictionaries of the future should be frame-based, they should provide a more thorough and precise representation of world, that is, conceptual, encyclopaedically-based knowledge. Research with a related scope of interest, called WordNet, is carried out in Princeton. By the way, cognitive grammar claims to be an encyclopaedically-based model of representing linguistic conceptualization.

LANGACKER: Your question is largely practical, and I'm not a very practical person. So my answer will be rather limited.

The notion of semantics being encyclopaedic in scope simply means that linguistic expressions, and lexical items in particular, are not vessels full of content. Instead they give us semi-structured ways of accessing conceptual content which is largely there for independent reasons. And there is no principled dividing line between what can be evoked via lexical items and general knowledge. I think this is very important to realize from a theoretical standpoint. The point is crucial if you want to understand language, how it works, how it's represented psychologically, and how it relates to the rest of cognition. But this doesn't translate into descriptive practice of any principled or any practical sort. Taking the point seriously would actually imply that it's impossible to write a dictionary, if you understand a dictionary as characterizing how speakers represent things in their own minds. A real dictionary is necessarily artificial, in the sense that it has to be limited in scope. But this doesn't mean that people shouldn't write dictionaries or grammars for practical purposes. And those practical concerns dictate what should go into them. What thoughts I have on the matter are not based on detailed research or detailed lexicography of either a practical or a theoretical sort. For an optimal dictionary, I think that examples are very important to show how expressions are actually used. Something that is really critical, and typically left out of dictionaries, are indications of the normal ways of phrasing things in the language. I know this from personal experience. I studied various languages in college, and was good at studying them the way they were taught in those days, and in some places still are. That is, I'd learn all the lexical items presented in a course, and mastered everything in the grammar book. But this itself does not guarantee real fluency or the practical ability to use a language effortlessly in everyday conversation. Part of the problem is register, part of it is diglossia, part of it is not being exposed enough to the culture and all the things members of the culture talk about from day to day. There is a vast amount of background knowledge required to bridge the gap 
between the way languages are classically taught and what is needed to use them in practice. But one particular factor stands out in my mind as essential. Given that you have learned all the rules in a grammar book, and all the basic vocabulary, you still face the following problem: if you want to say something, there might in principle be dozens, hundreds, or even infinitely many different ways to say it in the language - all equally grammatical using basic vocabulary. But speakers would normally say it in one particular way, out of all these options. The problem, then, is knowing how one normally phrases things in the language. That's a level which tends to be absent in language instruction, because it is not just a matter of grammar or of lexicon in the traditional sense. I cannot suggest a practical solution to the problem, but it does need to be addressed.

ANDOR: However, talking about constituency, more particularly about the compositionality of expressions, you suggest that "components are neither fixed nor predetermined in their semantic or phonological shape, but are flexibly construed to accommodate adjacent elements and the overall context; hence they may never have exactly the same value on any two occasions" (Grammar and Conceptualization, 1999b, 152). How can this issue be tackled in discussing the representation of meaning and meaning facets in dictionaries, that is, in sourcebooks of lexical organization and - for the future, when frame-based - of lexical relations?

LANGACKER: Well, that's a hard question. A first point is that there is indeed something that one can call the linguistic meaning (or meanings) of a lexical item. I emphasize flexibility in saying that what you can access through a lexical item is indefinite in scope, that you can reach into any associated domain of knowledge, and that you adjust and accommodate a lexical item's meaning to surrounding elements. These are not however equivalent to saying that a lexical item has no definite meaning, or that it can mean anything at all. It's not the case that anything goes. You have to avoid two equally wrong positions, and my formulation tries to do that. One position is that the meaning of a lexical item is fixed, determined, and quite limited, that we can figure out what it is, and that it's distinct from general knowledge. This is the classic view of the dictionary metaphor. The representation is generally assumed to be fairly small, roughly the size of actual dictionary entries (although Wierzbicka 1985 sometimes formulates very lengthy - albeit still limited - definitions). It is often conceived as being just a bundle of semantic features.

The other extreme is to say that, all right, since in the right context we can construe a term as meaning almost anything, lexical items don't 
have any fixed meanings. Things mean whatever we want them to mean. This, I think, is just obviously wrong. People know that words have meanings and that we stretch them to accommodate new circumstances. This implies that there is something we start from, something we stretch when needed.

So I talk about a lexical item being a structured and partially determined way of accessing encyclopaedic knowledge. A particular lexical item takes certain aspects of its referent (certain cognitive domains) as being central to its characterization, and others more peripheral. If there is no specific cut-off point as to what is potentially accessed through a lexical item, at least there are degrees of centrality, as a particular lexical item sets it up.

Which aspects of general knowledge tend to be evoked in using a lexical item is to some degree conventionalized. There is a gradation perhaps, but access is partially structured instead of random. At various places I give specific examples. My classic case is roe vs. caviar. If you think about it, we can access the total body of knowledge associated with either lexical item through the other one. People who know what caviar is know that it's made out of fish eggs, which is also called roe; and people who talk about fish eggs and use the term roe know it can be made into caviar. Effectively, then, the relevant portion of our encyclopaedic knowledge base is really the same for both. But if you use the term caviar, you expect it to more saliently invoke the finished product, the notion of expense and fancy parties, and all that. If you use the term roe, you are expected to be talking about fish reproduction, as opposed to what you eat on crackers at fancy parties. It takes some work to contravene those tendencies, as each lexical item accesses the same overall knowledge base from different directions. That's conventional, that's linguistic, that's built into what we can call the linguistic values of these lexical items. It is not a matter of their meanings being encapsulated, but rather of the different kind of access they afford to the shared knowledge base. This constitutes a difference in meaning.

Given that lexical items do have conventional meanings, it is still the case that context determines how in particular they are likely to be construed. This includes the effect of adjacent items that you alluded to in the passage quoted. Now, how to represent that in dictionaries, well, I don't know. Maybe dictionaries could do a better job of making it clear that lexemes give access to domains of independent knowledge, instead of just providing a concise definition. I'm not sure how that could be 
done. I think dictionaries are a little bit misleading by trying, in just a couple of lines, to offer a verbal definition which supposedly represents a lexeme's meaning. But a typical definition is not the sort of thing anyone would ever say. Dictionary definitions have a certain style, and they don't clearly indicate that we are accessing structured bodies of knowledge in a certain way.

I have just one other comment on these practical matters (which I have not thought about in any depth). It is simply that people are very adept at making sense of things, of flexibly construing lexical meanings to accommodate adjacent elements and the overall context. They make these adaptations so easily and automatically that they pose few problems in a practical sense. So perhaps dictionary writers don't have to worry much about it.

ANDOR: The role of 'domains' plays a critical role in your theory, which expresses the view that lexical items rank these domains. You also stress that related senses of lexical items (see p. 4 of the book Grammar and Conceptualization) comprise networks being linked by categorizing relationships. Let me quote: "[...] a lexical item evokes a set of cognitive domains as the basis for its meaning, and exhibits considerable flexibility in this regard. The access it affords is anything but random, however. First of all, the domains a lexical item invokes are primarily limited to those in which the entity it designates (i.e., its conceptual referent) figures directly. As part of its conventional value, moreover, a lexical item ranks these domains: it accords them particular degrees of centrality [...]" (Langacker 1999b, 4-5). All this certainly refers to the networks of conceptual structures that provide the sources of a relevantly mapped lexical representation. I mean, to networks such as scenes, frames, and scripts. I would say, lexical items are saliently mapped in and from such structures of cognitive activity. Why don't you use these terms referring to the particular type of conceptual activity rather than the considerably opaque term 'domain'? And why don't you use the notion of lexical-pragmatic 'salience', rather than 'ranking a domain'?

LANGACKER: 'Domain' is not one of my favorite terms. I needed to invent a lot of terms in formulating cognitive grammar, since there were so many notions that had no names previously, and since I thought a lot of prior terminology was infelicitous. Not every terminological choice I made to meet those needs proved optimal over what is now almost three decades. If I could invent the necessary terminology now, instead of having done so 25 years ago, I would make some other choices. So I don't totally defend

Acta Linguistica Hungarica 52, 2005 
all the terms I use. But there was a reason for using 'domain' instead of terms like 'scene', 'frame', or 'script', namely the need for a general term. 'Script' carries with it the notion of a sequence of actions, and that's too narrow. What I wanted was a general term to talk about meanings, or the conceptual content of meanings (as opposed to construal). 'Domain' allows me to talk about meanings in a general and coherent way, without making totally arbitrary divisions. For instance, we need to describe the source of the conceptual content for, say, a color term, as well as for something based on the restaurant script.

ANDOR: But how about 'frames'? Isn't that concept better for such purposes? Frames could be understood to be quite general, as opposed to scripts.

LANGACKER: You could also have included 'idealized cognitive model' (Lakoff 1987). Although Lakoff has said he understands the term ICM very generally, it is still too narrow. 'Frame' does come closest to being an adequate term. If I were doing things from scratch, I might well adopt 'frame'. But it would have to be in a totally general sense. Would Fillmore say that color space is a frame?

ANDOR: That's exactly the problem, that the term 'frame' has also been extensively very much abused. A lot of people who were talking about scripts and scenes and other kinds of scenarios, actually were thinking of frames rather than these other domains. So it has also been extensively abused, I should say. Which is a major problem. See Fillmore's alternative proposal to checklist theories of meaning (1975), his early steps to outline the theory of frame semantics (1982), and Schank and Abelson's classical work on frames (1977).

LANGACKER: Right. Fillmore uses 'frames', gives a list of things that he calls frames in his paper on frame semantics, but he didn't obviously cover basic domains - e.g., time, space, color space - which are also crucial to semantics. So that's my reason for using 'domain': the need for a general term. You also asked about 'salience' versus 'ranking'. Those are both very general terms covering certain aspects of construal. I have no principled reason for using the latter instead of the former in regard to domains.

ANDOR: Actually, for me, the most important aim was to clarify what 'domains' are and so on, using it as a general term, or perhaps, frame could have been a better candidate. That was the issue I intended to raise here. 
LANGACKER: Yes. There was a motivation, primarily the need to subsume basic domains as well as non-basic domains under one term. Fillmore was focusing on only certain kinds of notions as frames, though obviously the term could be generalized.

ANDOR: I would also like to ask you about active zones, concerning their role in serving as a discourse cohesive or coherence factor. In your work on active zones that I have had a chance to study, starting with your 1984 paper that appeared in the Berkeley Linguistics Society meeting handbook of that year up to fairly recent work, and also in Eve Sweetser's 1999 paper with ample reference to your work, the role of active zones is discussed within the framework of utterances rather than in texts. Perhaps it would be interesting to study their role in discourse organization, particularly as a discourse cohesive facet, and also as a factor in charge of the economical nature of linguistic, particularly of discourse representation. And we should also study their frame-related factors. Would this, in your view, be a feasible research project?

LANGACKER: I could answer just by saying "yes". But probably you expect something more.

I think the areas you mention are part of using the notion of 'active zone' in the first place. You cannot divorce this from questions of frames or domains, obviously.

ANDOR: That's exactly why I bring this up, from the point of view of providing some sort of organizing principle, or the kind of thing applicable for discourse interpretation.

LANGACKER: Yes. I don't think I ever conceived of the notion active zone as applying to utterances or spoken language, as opposed to texts. It was meant to be general, for any kind of language production.

ANDOR: I brought this up because when you were talking about active zones, you always had the utterance length kinds of structures highlighted.

LANGACKER: It is certainly true that I characterized active zones with respect to a relational expression and its arguments; I talked about a profiled relationship, and then the things that function as its trajector or landmark. That's the level at which I introduced the term and the purpose for which I introduced it. This ties the notion to a particular relational expression and associated nominals, e.g., a verb and then a clause. Maybe you are raising the question of whether a particular clause with a particular verb in it can be interpreted independently, or whether you sometimes have to look at the whole discourse context in order to

Acta Linguistica Hungarica 52, 2005 
determine the active zones. Another possible question is whether there might be some higher-level phenomenon that you could handle in a way analogous to positing active zones for verbs. Those are two different matters that could be investigated, but I haven't really thought about either one.

ANDOR: That's exactly the thing. I am also thinking of cases of synonymy. I have done quite extensive research in this issue. Taking verbs of jumping, for instance, why exactly people use a given member of a synonym set in a lexical field under the conditions of a certain context rather than another. Why do we tend to use the prototypical member of a set to overgeneralize, rather than use a specific one? Or, under what conditions do we use a specific one rather than the prototype? So I was thinking of a case where your concept of active zones could be very helpful in this domain, saying that, for instance, in certain types of contexts, you would choose to use a verb such as vault rather than jump. You would do that on such grounds because of the context, without mentioning some integral elements that go together with the verb, such as pole, for instance. I thought that choosing this particular verb rather than another one from a synonym set in some way could be related to active zones, which would provide the kinds of conditions relevant from the point of view of yielding, contributing to discourse coherence. That was my idea.

LANGACKER: I think that has to be worked out with particular illustrative examples to see concretely how it could be useful at that level. I do think it's worth looking at, it's a reasonable idea. To say more, I'd have to think in terms of specific cases.

ANDOR: Pursuing the topic of active zones a little bit further, let me ask your opinion about whether I'm right to say that the way you address active zones is closely related to the approach of certain pragmaticians, including Jason Stanley, François Recanati, Kent Bach and others, and, of course John Perry, in analyzing cases of unarticulated constituents, for instance in utterances such as

(i) Mary took out her key and opened the door.

in which a bridging inference has to be made by the hearer, resulting in with it or

(ii) He eats rabbit. (implying 'rabbit meat')

(iii) He wears rabbit. (implying 'rabbit fur'), 
demonstrating cases of free enrichment? Actually, the above-mentioned pragmaticians all happen to study the same examples that you analyze related to the issue of active zones, such as

(iv) I finished the book.

(v) John heard the piano.

And others. See, for instance, Recanati (2004). Which analysis by both parties, as I understand, refers to case-studies of the economy of linguistic representation. Is this a correct understanding?

LANGACKER: I wouldn't want to speak for those other analysts, because this is a little bit outside my usual scope of reading. But I think it's a good characterization for my standpoint. Yes, economy of linguistic representation is an important point here. As I tried to argue in talking about some of these examples, if you tried to be fully precise, instead of relying on the active zone phenomenon, you could never say anything. You can always be more precise. Every linguistic expression has to be oversimplified, and leave things out, and make a choice as to what will be explicit, and rely on established scenarios, established frames, etc. for people to fill in the details and make sense of it all. There are conventionalized ways of doing that, as well as free, new ways of doing it. This is all part of one big problem from my standpoint. The term 'active zone', as I said, was invented to cover a fairly narrow phenomenon, but I would never claim that the limitation is anything more than one of convenience, and a matter of what happened to attract my attention first. There is a danger in using the same term for too many things, in which case you need more specialized terms to distinguish subcases that are interesting for their own reasons. So there are different strategies here. Some terms I tend to use fairly narrowly, even though they could in principle be extended quite broadly. 'Reference point' is another one: anything could be a reference point phenomenon, if you want to think about it that way. But there are some things where that aspect is so special and central that it seems best to confine the term to those cases, at least for purposes of exposition. So that's what I tend to do. 'Active zone' is a term of that sort.

ANDOR: I would like to ask three more questions, time providing. The first concerns your notional approach to 'parts of speech'. You devoted considerable effort to discussing the case of verbs and nouns. I would particularly be interested in your way of thinking about the adjective category, which you consider to be an atemporal relation, that is to say, a 
state, summary scanned (as described on pp. 78-9 of Concept, Image, and Symbol (1990)). But first, what is your view about the predicative use of adjectives representing cases of the [ \pm stative/dynamic] distinction, such as in

(vi) John is hard-working.

(vii) John is malicious

(viii) John is being malicious.

and the the classic examples of

(ix) John is careful.

(x) John is being careful (with the vase).

I guess you would say that these examples demonstrate cases of processes.

LANGACKER: Well, you are raising some fairly complex issues here, and there's a lot going on in these examples. So we have to approach them from different angles.

First of all, I believe the characterization I gave is correct when fully explicated. When I say that an adjective profiles an atemporal relation, this doesn't mean that time is not involved. For example, in adjectives like early or late, time obviously is involved. What matters is how time is involved. When I describe a verb as profiling a temporal relationship (or 'process'), I mean by that two things. First, the relationship is conceived as evolving or extending through time. And secondly, in accessing it and using the expression as a verb, the relationship is scanned sequentially through time as opposed to being scanned in summary fashion. So a verb is temporal in both these senses: the profiled relation is conceived as extending through time, and at some level of processing we access it by scanning sequentially along that axis.

Time can perfectly well be involved in the first sense, but if we view it in summary fashion, by definition it is atemporal, or better 'nonprocessual', a term I generally use these days. Time is still involved, just not involved in both ways figuring in the definition of a verb. That is an important initial point of clarification.

Now, one thing we have to take account of is the fact that the examples you gave all contain the verb be. They do not use an adjective by itself, they combine it with be. So all of these are full clauses, and I would say that in every case what's being profiled is a process.

ANDOR: In Hungarian you would have iterative suffixation added to the root, and you would be using these words as verbs which have an adjectival 
base. In the Hungarian version of John is being stupid, for instance, you have the word buta (the corresponding adjective for stupid), and you have butáskodik (is being stupid), with rich morphology added to the root.

LANGACKER: That's comparable to what you are doing here. In effect, be is our English morphology. It's just a separate word sometimes, to some degree.

ANDOR: Under example (x), however, John is being careful with the vase, you could just use János ügyes a vázával in Hungarian, which would translate literally as John careful with the vase. That is, there would not be any be there in Hungarian.

LANGACKER: Well, I have enough trouble analyzing English without trying to analyze Hungarian, which I don't know. So you are bringing in still more complexities. I would not say that using an adjective to head a clause, thereby construing it as a process, always requires some overt morphological indication. That's certainly not true. An adjectival relationship can also be viewed as extending through time by virtue of being plugged into a particular construction which imposes this construal. It does not have to be done by a separate morphological element, but can just be a matter of constructional meaning. However you are still doing something beyond using the adjective in its basic sense. It just happens that in English we have a particular way of doing this in a construction which involves adding another verb.

So we have to strip away the contribution of be or that higher-level construction and talk about the meaning of the adjective itself. Of course, that's not really feasible here totally, either. Let's look at (viii) John is being malicious and (x) John is being careful. Those are, I think, the same phenomenon, as opposed to John is malicious, and John is careful. Here again, we are starting with be malicious or be careful. But in (viii) and $(\mathrm{x})$ these are not being used alone. There is a higher level of organization involved, and there are different ways of talking about it. What I want to say about (viii) and ( $\mathrm{x}$ ) is that in each case the be + adjective combination is not being construed as an imperfective verb but as a perfective verb. They profile bounded events. The overall event of be malicious is bounded, and be careful is bounded. They are thus perfective processes. We can say that this happens through a zero derivational process, or we can talk about them as representing a special, higher-level construction, making it an aspect of constructional meaning. I don't have any favorite way of talking about it at present. But the point is, if be careful or be malicious in its basic sense describes a person having a certain prop- 
erty that extends indefinitely through time, in (viii) and (x) we have a use designating an event, an occurrence, a manifestation of this property through some bounded span of time. The sentences could be translated as something like act malicious or act careful (although act is a bit too strong). And because the complex predicate is construed as perfective, it takes the progressive (which in English is limited to perfectives), which has to be used for present time. There is thus a difference between just ascribing or describing a property versus describing a manifestation of a property in one bounded occurrence. That is what these particular examples hinge on. I suppose Laura Michaelis would talk about this in terms of 'coercion' by a higher-level construction, and I'm happy with that, too. That's one way that I could approach the phenomenon. So you see, there are various dimensions to your question. We have covered several already. Did you have something with example (vi), John is hard-working, other than what we've already discussed?

ANDOR: Well...

LANGACKER: Now, there is something very deep and important here that I don't yet have a good grasp of. That is this notion of a 'property'. First of all, any adjectival property, when it's actually manifested, is manifested through time, either a point in time or a time span of indefinite extent. One way or another, time is involved in ascertaining or observing an adjectival property. The temporal aspect is more salient in some cases, e.g., in John is hard-working, as opposed to John is tall. Just by glancing at a photograph we can see that John is tall. But for John is hard-working, you have to observe him on various occasions for extended periods. However, the two adjectives are parallel linguistically, in that both of them designate the situation of that property being characteristic of the person, as either a locally or globally valid ascription. That's different from the actual manifestation of the property, or the observation and verification of it. You have to sort all these things out. What I think is a rather deep and important problem, one I haven't worked out to my own satisfaction yet, is to specify what happens conceptually in converting these various observations into the ascription of a constant property.

ANDOR: Which is very exciting.

LANGACKER: Yes. And it's not just adjectives. The same holds for mental state predicates. For example, when I say that John believes that $X$, probably at the moment I utter the sentence John isn't even thinking about $X$. There are probably very few occasions in his life when he 
thinks about $X$, but he can still believe that $X$. So, having this belief is a kind of stable property of John, or at least it's something constant. But it's only occasionally manifested. So we have this difference between the manifestation of something and the stable aspect of having it, whether it's a belief or a property like tall, hard-working, or whatever. Exactly how to think about the conceptual step in going to that level is something I'm not sure about yet. But clearly we do it, and it's manifested linguistically in the difference between perfective and imperfective expressions. The resulting expressions (e.g., John is hard-working) are imperfective in form, because we are talking about something that's stable and fixed. But what exactly is it that we are talking about? I know there are classic philosophical problems involved in this. I won't address it from that direction, but I'd like to address it from a conceptual direction in more detail than I have in the past.

ANDOR: Studying the semantic value of possessive elements and possessive constructions seems to be one of your favorite topics of investigation. The most recent paper I read on this issue was a conference lecture given as a plenary talk in Braga in 2003, published in 2004, in which, I believe correctly, you expressed an anti-localistic view (Langacker 2004, 111-2), opposing the views of case grammarians such as John Anderson (1971). Here, I would like to inquire about your view concerning the pragmatics of possessives in structures where the Saxon genitive or a possessive pronoun is used. Let me take just three examples:

(xi) John's dinner was very tasty.

(xii) Their knives were very sharp.

(xiii) Their film was very interesting.

All three demonstrate the same issue: the possessor can be understood either as an Experiencer (perhaps even as a Locus, à la Anderson and the localists), or as an active controller of an act of production, i.e., an Agent. When asked to associate, informants show a significant difference in making judgements about the role. How would you interpret, describe this difference in interpretability in your own framework? Certainly, referring to some sort of an attenuation of the active controller role would not work in such cases. The case is interesting, as we would be facing exactly the same issue if the sentences were translated into Hungarian, for instance.

LANGACKER: The problem I face here is how to answer that question without delivering the entire paper. First of all, I think any of these

Acta Linguistica Hungarica 52, 2005 
sentences could be interpreted in lots of different ways, or any of the nominals can certainly be interpreted in lots of different ways. So there is nothing fixed about their interpretations. What you are alluding to here are their default interpretations.

ANDOR: For instance, whether John prepared the dinner, or perhaps he ate it.

LANGACKER: Right. You'd think of those interpretations, or maybe one in particular, rather than dozens of other possibilities, e.g., that John's dinner is the one he is responsible for delivering or poisoning. Those wouldn't come to mind.

ANDOR: But still, when people are asked to associate, you know, one rather than another type of association for a certain kind of context or frame would pop out as most typical and perhaps most salient. I wonder why that is. From among a number of chances available to them, people still stick to certain sorts of things, they spontaneously recognize some sort of saliency. Like in most cases, for instance, in the utterance Their knives were very sharp, I believe they would typically think of the producers. Their dinner was very tasty for somebody who ate it or had it, or something like that, rather than referring to somebody who prepared it. But it's a matter of interpretation within a domain or a frame.

LANGACKER: Right. All these invoke some frame, at least implicitly, for their interpretation. You can bias it with the following adjective. But even without the adjective, there are factors like familiar scenarios, standard uses, and the frequency of occasions of talking about particular kinds of things. These result in different degrees of salience for various interpretations.

ANDOR: Let's take one more of these examples, for instance, Their holidays were excellent, thinking of whether they are travel agents or perhaps clients of them.

LANGACKER: Sure. Any plausible scenario you can come up affords a viable interpretation, but for some interpretations it takes a lot more work to construct an appropriate context. The kinds of factors mentioned bias things in certain direction. Now, from my standpoint that's interesting and very true. But it wasn't what I was talking about.

ANDOR: I know.

LANGACKER: The question I was addressing was: What can you say about the meaning of this Saxon genitive construction in general? You don't want to list all the individual kinds of relationships there can be 
between possessor and possessed, and say that that's all there is to it. This won't work, since there is no end to the possible relationships that might be involved, if you are talking about things at the level of eating something, making something, etc.

At the other extreme, you can say that there is no semantic value at all that the possessive construction or the possessive morpheme has; because it's so varied, there is just no content that all uses share. And if you're strict about the word 'content', maybe I would agree with that, but I wouldn't agree that there is no shared meaning at all. Possessives are not semantically vacuous. I think the possessive construction (and/or the possessor morpheme) has a schematic meaning as well as prototypical values. But the prototype could conceivably vary from noun to noun. Obviously, only some things are likely to be owned, so ownership is only relevant with certain kinds of nouns. There are only certain kinds of things we make, and so forth. But what I try to show is that the reference point model naturally accounts for the schematic level of characterization.

Secondly, I try to show that the reference point relationship-mentally accessing the target through the reference point - represents the subjective construal of all of the objective kinds of relationships that are typical of possessive constructions, including actively controlling something, or owning something, holding something, etc. Conceptually, those relations (controlling something, holding something, making something, seeing something, having exclusive access to something, etc.) are directional and asymmetrical. Conceptualizing them involves mentally accessing the possessor and the possessed successively, in that order. This sequence is inherent in conceiving of $X$ controlling $Y$, in any of those varied ways. I assume that one crucial aspect of this conception is tracing a mental path from $X$ to $Y$ : evoking $X$ and then using that as a basis for evoking $X$ interacting with $Y$. Schematically, that's all possession amounts to: first evoking the possessor, which makes it possible to then evoke the possessed. This subjectively construed relationship is the schematic value of the reference point relation, and that's what all possessives have in common. The reason certain orders are natural, so that we generally can't reverse things and say, for instance, the dinner's John, is precisely that specific instantiations imply a certain directionality just to apprehend them in the normal way.

ANDOR: My final question concerns the issue of linguistic modularity, that of the human language faculty. Do you share the modular view of language as outlined by Fodor (1983), that is, a view according to which 
there exists a language module which is encapsulated, its output representation is shallow, and which does not communicate freely with other modules or the central systemic units of processing? Or, perhaps, would you sympathize with Jackendoff's model of representational modularity, which outlines a number of interfacing sub-modules of the linguistic system (2002)? Once, on p. 13 of Vol. 1 of your groundbreaking work (1987), you expressed the view that knowledge about language is not advanced or mature enough to be able to tackle such issues. Do you still hold the same view at the current level of the state of the art?

LANGACKER: I am uncomfortable with any modular view of language. One reason this is tricky is that it's clear that the brain is not just a homogeneous bank of neurons. I mean, the brain is organized in a modular fashion in many respects. There are columns of neurons that do particular things, areas of the brain that do particular things in coordinated ways, and so forth. There is certainly modularity in how cognition works at the brain level. And if you look at any particular linguistic phenomenon, like a clause or just a noun phrase, you can talk about different features of it as independent problems of analysis. You can talk about the problem of grounding, or of conceiving a physical object, or the problem of categorization. Those are separate problems, and there can be many such problems separable to some degree as issues. Linguists have a tendency - if you question modularity - to cite cases like these as showing the need for a modular view. There are however different things that might be called modularity. The question is whether these include the particular things that linguistic theorists like Fodor and Jackendoff have been dedicated to. Is the language as a whole a module? Or particular subcomponents of a language, like lexicon, syntax, or morphology? I think not, although I would not presume to have convincing arguments that would sway the opinion of a modularist. This is a vast question, and not one I feel qualified to focus on personally in my own work. I think I'm pretty clear about the matter, if I wasn't in 1987. I think those particular kinds of modules are gratuitous from the linguistic standpoint. I don't believe, for example, in any distinction between the lexicon, as people call it, and the syntax. I think it's an erroneous distinction based solely on tradition. That's the clearest case. But the same holds for the language as a whole. Certainly there are kinds of knowledge I consider to be linguistic. But typically these result from drawing together and exploiting independently existing phenomena. They are packaged in a certain way, so the resulting package is specifically linguistic. But lin- 
guistic units are not independent of the rest. Encyclopaedic semantics is an obvious and simple example. It just doesn't make any sense to try and separate what's linguistic and what's non-linguistic from the meaning of a lexical item, for reasons argued in other places.

Here's the way I like to think about such matters. It concerns both modularity and the question of innateness, which, of course, is closely tied up with it. We can start with this basic question: Is there an innate language capacity, or an innate universal grammar? At one level the answer is obviously "yes". We have inborn bases for learning languages, we have a compulsion to learn languages when we are children - that's all wired in. The next question is: Are these specifically linguistic? Or is it all done on the basis of more general abilities? That leads to the issue of whether there is a language module, which is a different question. There is a universal basis for learning language, but certainly all kinds of other knowledge and abilities have to be in place and contribute to learning a language. These include pragmatic factors: being able to know that people have intentions when they are speaking, and to apprehend those intentions. These skills are typically ignored by Chomskyans when they argue for the impossibility of learning languages. Obviously, language learning cannot occur by itself; it requires a certain foundation. But given this foundation, I believe it is all describable in terms of semantic structures, phonological structures, and symbolic links between them. There's nothing special like a syntactic component with irreducible syntactic primitives, etc. I am willing to believe that something specifically linguistic is involved, not just general knowledge. I'm pretty sure that we don't learn languages just on the basis of general abilities. I think we have a specific language learning capacity, which partially shapes linguistic structure. But what is it that's specifically linguistic? I don't believe there's any particular content that's specifically linguistic. The analogy I like to draw is with the physical organs of speech. We produce speech with the lungs, the trachea, the vocal chords, the mouth, the nose, the lips, the tongue, the teeth, and so forth. But these organs of speech are all there for other reasons, independently of speech. In the evolution of language they have been adapted, adjusted, and fine-tuned. These adaptations are obviously innately specified — we're born with the vocal apparatus in a certain configuration that chimpanzees don't have. Still, nothing is physically involved that isn't more broadly grounded and doesn't have other uses in the human organism. It is only the particular detailed configuration this apparatus assumes, reflecting the particular 
adjustments that have occurred, which make it all work together to give us articulate speech. These are innately specified, and specifically for linguistic purposes. And for the rest of language, I'd like to think of it as being analogous. Conceptualization, semantics, symbolization, and from these grammar - they all rely on things which are independently there and have other functions. But we do much more with them than we could if it were not for innate specifications. It's a matter of tweaking the system, so to speak. And those tweaks are the specifically linguistic innate specifications. Language is not modular in that sense. This is a non-modular view of linguistic uniqueness.

ANDOR: We, who have followed the development of your cognitive grammar paradigm with great attention on a regular basis, all know the starting point, the initial motivations for it. All of us would now be greatly interested in your plans to develop or extend your theory, and we would like to know what are the topical issues of your research interest for the immediate or the more distant future.

LANGACKER: I'd like to know that, too. It's a hard question, since there are major problems that need a lot of work. These include things I've reflected on in recent work and have to be investigated at a deeper and more extensive level. One is the need for a cognitive lexicography along the lines of the constructs suggested in cognitive grammar. I am thinking of a program analogous to what Wierzbicka does with her natural semantic metalanguage (1996). I cannot imagine personally undertaking anything on a scale comparable to hers, examining so many lexical items across so many languages. I would however like to work out representative areas of the lexicon in comparable semantic detail, specifically from the cognitive grammar perspective. Since I'm now formally retired, there may be time to have fun with this in coming years. It's important to see just what is involved.

Two themes have come up a lot in recent work. One is "fictivity" (or "virtuality"), e.g., the fictive motion that Talmy (1996) and others have written about. Fictivity is so extensive that I'm not convinced we ever talk directly about actuality. Perhaps we always talk about fictive entities, relating them to actuality only secondarily. But whether that's true or not, fictivity is a certainly major theme which I've written about a lot. I suspect we are only beginning to understand its pervasiveness in language.

Next is "dynamicity", a term that alludes to the time course of any conceptualization. It extends naturally to the time course of conceiving 
the form and meaning of a complex expression, like a clause or a sentence. And that shades into questions of grammatical processing - the time course of it, what's going on semantically at each stage, etc. Obviously it also ties into discourse, which I am gradually becoming more involved with. Eventually there needs to be a unified view of semantics, grammar, processing, and discourse. While I have ideas along these lines, they are far from being well-developed or ready to present in detail.

Those are some big themes in the back of my mind. They are all very closely related. In choosing topics, I generally work on what I have to at a certain period in order to get a paper ready for a conference or a volume. In a sense these practical matters drive the agenda. But the topics are all related and mutually informing, they push in the same general direction. I think it has worked out pretty well and will continue to in the future. In any case, the topics I mentioned should be quite important.

One concern is to make it clear how all of the specifics of the model and this way of viewing grammar actually follow from an initial focus on the social-interactive context of speech. It is actually fairly clear in my work, if you really look at it. For instance, I talk about usage events as the basis for all linguistic units, I talk about things like grounding, which is where the speaker-hearer interaction meets grammar. All the way through I have ways of accommodating the social side of things, the cultural side of things, the interactive side of things, the discourse side of things. But this has always been looked at in piecemeal fashion. I am often accused of talking about pure conception and not focusing on these issues. But if you look at the framework and what I actually have talked about, that's not really accurate.

One thing I'm gradually working around to, and hope to do seriously at some point, is to articulate the framework in a way that starts with the social-interactive and the contextual-cultural basis of language, showing how the rest all emerges from it, instead of going in the other direction. This may be more a matter of presentation than of different substance, but I think it's important to work it out along those lines.

Those are some major issues that I'll be thinking about in the future.

ANDOR: And we might be expecting some more of those big volumes in the future.

LANGACKER: Big ones, small ones, or articles, I don't know. But certainly I'll keep writing for a while. 
ANDOR: You are a very happy man, I should say, having these kinds of ambitions which, I think, is great for somebody who is working as seriously as you do on these issues.

LANGACKER: Well, I think I'm actually just getting started, in terms of figuring out these problems.

ANDOR: But this is exactly the fantastic thing about it. So, Ron, thank you very much for giving me this interview. It certainly has significantly enriched my understanding of your theory and I do very much hope that it will influence its readers in the same way.

LANGACKER: Thank you for taking the time, as well as for the interest and all the preparation.

\section{References}

Anderson, John 1971. The grammar of case: Towards a localistic theory. Cambridge University Press, Cambridge.

Bloomfield, Leonard 1933. Language. The University of Chicago Press, Chicago.

Croft, William 2001. Radical construction grammar. Oxford University Press, Oxford.

Fillmore, Charles 1975. An alternative to checklist theories of meaning. In: C. Cogen (ed.): Proceedings of the First Annual Meeting of the Berkeley Linguistic Society, 123-31. BLS, Berkeley, CA.

Fillmore, Charles 1982. Frame semantics. In: I-S. Yang (ed.): Linguistics in the morning calm, 111-37. The Linguistic Society of Korea, Hanshin.

Fodor, Jerry A. 1983. The modularity of mind. An essay on faculty psychology. MIT Press, Cambridge MA.

Goldberg, Adele 1995. Constructions. A construction grammar approach to argument structure. The University of Chicago Press, Chicago.

Jackendoff, Ray 2002. Foundations of language: Brain, meaning, grammar, evolution. Oxford University Press, Oxford.

Janssen, Theodorus A.- Gisela Redeker (eds) 1999. Cognitive lingusitics: Foundations, scope, and methodology. Mouton de Gruyter, Berlin \& New York.

Lakoff, George 1987. Women, fire, and dangerous things. The University of Chicago Press, Chicago.

Langacker, Ronald W. 1984. Active zones. In: C. Brugman-M. Macaulay (eds): Proceedings of the Tenth Annual Meeting of the Berkeley Linguistics Society, 172188. BLS, Berkeley CA.

Langacker, Ronald W. 1987. Foundations of cognitive grammar. Theoretical prerequisites. Vol. 1. Stanford University Press, Stanford.

Langacker, Ronald W. 1990. Concept, image, and symbol. The cognitive basis of grammar. Mouton de Gruyter, Berlin. 
Langacker, Ronald W. 1999a. Assessing the cognitive linguistic enterprise. In: JanssenRedeker (1999, 13-59).

Langacker, Ronald W. 1999b. Grammar and conceptualization. Mouton de Gruyter, Berlin.

Langacker, Ronald W. 2003. Construction grammars: Cognitive, radical, and less so. ICLC Congress, Logroño.

Langacker, Ronald W. 2004. Possession, location, and existence. In: A. Soares da Silva - A. Torres - M. Gonçalves (eds): Linguagem, cultura e cogniçao, Vol. 1, 85-120. Almedina, Coimbra.

Recanati, François 2004. Literal meaning. Cambridge University Press, Cambridge.

Schank, Robert - Robert Abelson 1977. Scripts, plans, goals, and understanding. Lawrence Erlbaum, Hillsdale, NJ.

Sweetser, Eve 1999. Compositionality and blending: Semantic composition in a cognitively realistic framework. In: Janssen - Redeker (1999, 129-162).

Talmy, Leonard 1996. Fictive motion in language and "ception". In: Paul BloomMary A. Peterson - Lynn Nadel-Merrill F. Garrett (eds): Language and space, 211-276. MIT Press, Cambridge MA.

Taylor, John 2002. Cognitive grammar. Oxford University Press, Oxford.

Wierzbicka, Anna 1985. Different cultures, different languages, different speech acts. In: Journal of Pragmatics $9: 145-78$.

Wierzbicka, Anna 1996. Semantics: Primes and universals. Oxford University Press, Oxford.

Address of the author: József Andor

Department of English Linguistics

University of Pécs

Ifjúság u. 6.

H-7624 Pécs

Hungary

andor@btk.pte.hu 